Carmen Werder, WESTERNWASHINGTONUNIVERSITY, carmen.werder@wwu.edu Shevell Thibou, WESTERNWASHINGTONUNIVERSITY, shevell.thibou@wwu.edu Scott Simkins, NORTH CAROLINA A\&T STATE UNIVERSITY, simkinss@ncat.edu Karen Hornsby, NORTH CAROLINA A\&T STATE UNIVERSITY, klhornsb@ncat.edu Kali Legg, WESTERN WASHINGTON UNIVERSITY, leggk4@students.wwu.edu Tawanna Franklin, NORTH CAROLINA A\&T STATE UNIVERSITY, trfrankl@aggies.ncat.edu

\title{
Co-Inquiry with Students: When Shared Questions Lead the Way
}

Followed by Student Response by Roselynn Verwoord

\section{ABSTRACT}

Co-inquiry represents a distinctive relational model for partnering with students in SoTL that focuses on the process of seeking itself, and in particular, the importance of shared questions. We use case studies from two institutions to illustrate co-inquiry in action and highlight the importance of shared questions in changing the faculty-student dynamic in ways that foster deep learning. Clarifying the nature of co-inquiry around shared questions represents a valuable way to effectively strengthen and enrich learning not only for students, but also for everyone involved in SoTL partnerships with students. The programs described here illustrate how co-inquiry can work as a form of institutional SoTL, providing valuable and authentic opportunities to incorporate student voices - and shared questions-in effecting institutional change.

\section{KEYWORDS}

SoTL, partnership with students, co-inquiry, institutional SoTL

It is important that students bring a certain ragamuffin, barefoot, irreverence to their studies; they are not here to worship what we know, but to question it.

Jacob Bronowski, “The Ascent of Man”

Be patient toward all that lies unsolved in your heart, and try to love the questions themselves.

Rainer Maria Rilke, "Letters to a Young Poet"

The last decade has seen an increased desire within the SoTL community to collaborate with students in a rich array of ways. Healey, Flint, and Harrington (2014, and in this issue) provide a valuable conceptual model delineating multiple forms of student-faculty partnerships. Their model describes four distinct but interrelated partnership categories:

1) Learning, teaching, and assessment

2) Subject-based research and inquiry

3) Scholarship of teaching and learning, and

4) Curricular design and pedagogic consultancy 
Healey, Flint, and Harrington (2014) also highlight the need to better understand the relational dynamics involved within each category, noting that work in each area "often focus on the activities undertaken rather than on the decision-making processes involved” (p.3).

Some authors have emphasized that faculty-student partnerships are a "principle of good practice" (Felten, 2013) and perhaps even serve as a threshold concept for educational development (Werder, Thibou, \& Kaufer, 2012). Others describe how to engage students as partners in the study of teaching and learning (Werder \& Otis, 2010; Healey, Flint, \& Harrington, 2014; Cook-Sather, Bovill, \& Felten, 2014). Yet, no explicit conceptual framework that we are aware of exists for understanding the critical role that shared questions play in doing this kind of SoTL partnering, despite a history of referencing the phrase co-inquiry with students (Werder 2014). ${ }^{1}$ As the Partnership Learning Communities model (Healey, Flint, \& Harrington, 2014) highlights, student-faculty partnerships can take multiple and complementary forms, sometimes with overlapping characteristics. Our purpose here is to illustrate the distinctive nature of co-inquiry with its emphasis on shared questions in an effort to help others create, recognize, and strengthen their own co-inquiry initiatives.

Using examples from two institutions, Western Washington University (WWU) and North Carolina A\&T University (NCAT), we explore partnerships with students in the scholarship of teaching and learning (SoTL) category of the partnership model. In the process, we focus particular attention on what we describe as "co-inquiry," a distinct form of student partnership grounded in shared questions and an ongoing process of shared inquiry. Our two case studies illustrate what we refer to as "institutional SoTL," where the shared questions make visible student voices that inform institutional change. Institutional SoTL differs from what in the U.S. is called institutional research or institutional assessment due to its reliance on open-ended inquiry focused on discovery rather than on summative assessment. While the two case stories feature different decision-making processes in their distinct institutional contexts, we offer them side-by-side because they both deliberately foreground the critical role of shared questions.

\section{Background}

Etymologically, co-inquiry (from Middle English "enquiry”) denotes sharing a process, i.e. the act of seeking itself. Rather than focusing on an end product, co-inquiry emphasizes a shared conceptualizing process involving the co-development of questions to explore. Co-inquiry relies on the theoretical construct of inquiry-based learning that allows students to critically analyze information by asking their own questions. In the context of this article, shared questions are a form of open inquiry "where students formulate the questions themselves" including participating in the "full inquiry cycle" (Spronken-Smith \& Walker, 2010, p. 727). The nature of co-inquiry is such that one question typically leads to another and thus animates and sustains a relationship among those seeking answers to these questions. Therefore, at the heart of co-inquiry is the critical role of shared questions and the cogeneration of those questions.

Another component of inquiry-based learning highlighted throughout this piece is the role of a facilitator in co-generating shared questions. Inquiry-based learning consists of "constructing new knowledge and understanding, [and] the teacher's role is one of a facilitator [which is] a move towards self-directed learning" (Spronken-Smith et al., 2011, p. 15). Learning through inquiry is the ability to move away from direct learning to a more constructivist approach of teaching that emphasizes thinking and understanding (Zahorik, 1995). 
We contend that developing shared questions collectively serves as a facilitative mechanism in itself that enables learners to make this shift collaboratively. In the case studies that follow, shared questions center on issues of institutional importance and inform institutional change, hence the name "institutional SoTL" for the particular type of co-inquiry we highlight here.

The WWU case features the Teaching-Learning Academy (TLA), a dialogue forum aimed at studying and enhancing the university's learning environment. TLA participants, which include faculty, staff, and students from across campus as well as community members, jointly develop a big question about teaching and learning in the fall quarter to investigate collectively the rest of the academic year.

The NCAT case features the Wabash-Provost Scholars Program (WPS), which trains undergraduate students to conduct campus-wide assessment related to key strategic goals at the university, such as improving graduation and retention rates, increasing transfer student enrollment, and broadening diversity (a particularly interesting issue at an historically black college and university (HBCU) $)^{2}$ Students, faculty co-directors, and administrators jointly develop questions each semester that address specific institutional goals and form the basis for student-led, student focus groups and other assessment initiatives.

In the following sections, we outline the distinct decision-making processes embedded in these two co-inquiry cases involving students while highlighting their core commonality: institutional inquiry grounded in shared questions jointly developed in a communal process.

\section{Case study 1: co-inquiry in the teaching-learning academy at Western Washington University}

The WWU Teaching-Learning Academy (TLA) provides an institutional example of co-inquiry in action. Now in its $16^{\text {th }}$ year, the TLA moved from the Vice-Provost for Undergraduate Education's office to the Libraries in 2010 to become a program partner in the emergent Learning Commons. Throughout its history, the TLA has served as a dialogue forum that includes students, faculty, and staff (and, more recently, community members). Participants meet every other week across four dialogue sessions in an effort to deepen individual and collective understanding of teaching and learning relationships as part of enhancing the university's learning environment. Early in its history, the director deliberately inserted a hyphen in the program's name to emphasize that the programmatic focus is squarely on understanding the relationships between teaching and learning, between teachers and learners.

Every quarter (except summer), 75-100 people participate in the TLA dialogue sessions with approximately one-third being faculty, staff, and community members and two-thirds being students, though sometimes the balance shifts closer to half and half. The faculty, staff, community members, and some students participate on a volunteer basis, some for a quarter, some for multiple years. Other students participate as part of a course expectation, including students in our First-Year Interest Group (FIG) seminars, an upper-division communication course on civil discourse, and a communication practicum that earns them one credit for participating and facilitating small dialogue groups. Five to seven students serve as TLA staff who participate, facilitate, and scribe as part of their work-study positions. Student participants repeatedly note that they have to come back in the fall "to find out what the year's big question is going to be" and subsequently to find out how the TLA will answer it. A number of students participate over multiple quarters, some for their entire academic careers, and frequently as volunteers without earning credit. 


\section{Question-generating process}

In the fall quarter, TLA participants collectively develop a big question regarding learning to address for the rest of the year. Participants draw on their own lived experiences in (and near) the academy in constructing the shared question. They work together to craft one overarching question that results from a question co-generation process that honors the interests, views, and aspirations of the TLA participants for that quarter. Akin to slow cooking, the TLA model of slow talk, with its format of structured informality, enables participants to follow their own questions until a shared big question emerges by the end of the term.

This structured informality relies on a facilitative process that ensures what Harland et al. (2015) suggest in making a case for "slow scholarship": - a deliberative process that allows for "integrated inquiry" and a pace that provides the necessary time to develop higher-order thinking skills "with opportunities for developing the skills of argumentation, discussion, and reflection" (536). However, the TLA's model relies on an additional distinction that communication experts Ellinor and Gerard (1998) make in proposing a conversation continuum that goes from dialogue on one end to debate on the opposite end. In the process they distinguish between dialogue as "creating shared meaning among many (views)" and discussion as "gaining agreement on one meaning" (p. 21). By design, the TLA has adopted dialogue as their primary communication mode, and sessions begin each quarter with an introduction that provides Ellinor and Gerard's conceptual distinction as a ground for the conversations that are to come. While TLA members do settle on one big question at the end of each fall quarter, their search for that overarching question (taking all of fall quarter) and their subsequent search for answers (during winter and spring quarters) involves a divergent, dialogic process.

A hallmark of this dialogic model is a deliberate effort to flatten the usual academic hierarchy. From the outset, participants introduce themselves, not by their departments and titles, but frequently by a question that they wonder about or something they want to know more about. At the beginning of each quarter, participants review and endorse shared "conversational agreements," originally composed and periodically revised by the civil discourse class, which provide a set of simple ground rules:

- Be respectful - listen patiently with the primary goal of understanding;

- Be open-work to understand differences, not to erase them;

- Be direct-say clearly what you expect from others and ask question when you don't understand;

- Be present-resist technology, engage actively and contribute, but know that silence sometimes is all right too;

- Be ethical-respect the human rights of all.

To accommodate diverse schedules, the participants meet in four different sessions for 80 minutes every other week. To start each session, the whole group facilitator who is either the TLA director or the program coordinator (1) overviews the session's agenda, (2) reviews the highlights from the last TLA sessions, and (3) shares the dialogue prompt for that day's conversation which the TLA student staff help craft during the off-week. During this time, participants share announcements of upcoming teaching and learning events, read highlights from the last TLA conversation round, and review the conversation prompt for that session's dialogue. Then participants move into smaller breakout groups facilitated by the communication practicum students who have studied and reflected on the Ellinor and Gerard article. These student facilitators use the conversational agreements to ensure that all participants have equal airtime to raise both response comments and questions, always questions. Frequently, the small group conversations begin with "uninterrupted air time" to ensure that quieter 
participants, especially students, have a chance to articulate their ideas without interruption from others, especially faculty who often need to learn to curb their inclination to talk too much).

Participants repeatedly say they especially value the deliberate efforts to flatten the usual institutional hierarchy. Instead of feeling as if they have to defer to their elders (or even their youngers), the process relies on listening to individual voices and finding shared meaning. The institutional location of the speaker does not matter. Students and other participants alike praise the non-hierarchical model because it enables them simply to listen and participate without having to assume full responsibility for where the process goes. Students note that the deliberate efforts to flatten the hierarchy in the dialogue make all the difference in their willingness to share their ideas and, especially, their questions.

While the TLA's fall quarter focus on generating the big question highlights how central questions are to this model, other features of the dialogue dynamic also illustrate the deliberate efforts to surface questions. They also often remark on how much they appreciate being able to influence the actual form of the big question. For example, one year the big question was in its last stages of formation as "What keeps us from authentic dialogue across differences?' when student after student in the dialogue groups questioned the word "authentic," which one student termed a "teacher word." Ultimately, the group settled on "genuine," thus opening up a pathway for more collective ownership of the question itself. The TLA's emphasis on a flattened hierarchy supports inquiry-based learning as a meaningful environment for learners where they can express, challenge, and examine preconceptions and misconceptions in a dynamic non-threatening way (Bevevino, Dengel, \& Adams, 1999).

\section{Question-answering process}

While the TLA process centers on identifying shared questions, participants also engage in answering them. During winter and spring quarters, participants shift their attention to a "going public" process that involves action steps and, usually, institutional change initiatives. In addressing the big question, participants draw on their own lived experiences as well as their aspirations and information from outside sources. This collective study frequently results in creating various kinds of guiding principles and practices documents that the staff circulate across campus to various groups depending on the big question topic, as well as developing action proposals that the TLA enacts.

For example, in 2010, the TLA big question "What makes for reflective learning, and how do we enhance it?" resulted in a list of reflective teaching practices that became part of a compendium of reflective activities and practices sent electronically to all faculty listservs. That year's study also resulted in a proposal to create a garden on campus that would serve as an inviting place for pausing to reflect. The proposal went to the Western Foundation, which identified an initial donor to begin the WWU Reflective Garden, which now occupies a prominent plot on campus near the library. Based on specific recommendations from TLA members, an Art Department alumna and owner of a garden design company created a landscape design for the garden. Additional external donations have provided benches as well as trees, plantings, and a metal entry sign acknowledging TLA's role in launching it. With continued donations from TLA alumni, the Reflective Garden continues to grow.

Sometimes the co-inquiry leads to a new event. The 2013-14 big question "How do we ignite individual passion, purpose, and potential to co-create a culture of trust?" prompted TLA to develop and host a spring event. That year's study of trust building revealed an emergent principle: Working together in service fosters a sense of trust that can lead to deeper learning. That finding led to a proposal for sponsoring a "Connecting Communities" event in April 2014 during National Volunteer Week, bringing together people from campus and surrounding neighborhoods in a day of shared service. The result was a successful Connecting Communities in Service Day with 85 participants from on- and off-campus who 
provided service for local organizations as well as on-campus including doing clean-up work in the Reflective Garden. TLA sponsored the event again in spring 2016, and it promises to be an annual event.

\section{Impact on individuals}

While these programmatic outcomes demonstrate the effectiveness of the TLA co-inquiry model in terms of enhancing the university learning environment, survey data also demonstrate the influence it has on individual participants. Each quarter, participants respond to a brief survey asking what, if anything, they gained from their participation in TLA. Because the closing survey occurs during the final dialogue round each quarter (as well as being available electronically), the response rate averages $80+$ percent, and $100 \%$ of the respondents uniformly report gains from participating. The majority of the survey responses regularly report two particular patterns of gains: their realization about how much others care about them and the way TLA participation gives them a greater sense of agency for their own teaching/learning. Their responses also consistently point to the role of the co-inquiry process in promoting learning - about themselves, each other, and the learning process itself, as evidenced in the following survey responses (with emphasis added):

- "I gained a greater sense of connection to WWU through dialogue with a shared purpose; this really helped me understand different viewpoints." (student participant)

- "The TLA connects me with students and colleagues in other disciplines that I would have never known. I always leave the dialogue sessions thinking more deeply about teaching and learning." (faculty participant)

- "I have come to understand the professors on campus as not just my teachers, but as my learning colleagues." (student participant)

- "Every time I attend a TLA session, I make a new connection-either between myself and another individual or between ideas that I have floating around half-formed in my head." (staff participant)

- "The TLA has really changed the way I view my education. I care more about how I learn and not just what I learn." (student participant)

- "I get to see others on campus thinking about ways to improve teaching and learning. The TLA lets me connect with people on and off campus, to share ideas and reflect together." (student participant)

As these comments suggest, when a partnership model deliberately highlights a shared purpose and process, focusing on co-inquiry as an ongoing process of discovery, the learning is genuine, personal, and transformational.

In fact, the learning often extends beyond the TLA itself. For example, co-author Legg, a multiple-quarter TLA student participant, was able to recognize the emergence of co-inquiry in a general education course that she was taking, leading to a powerful learning experience. The course focused on salmon recovery and enrolled twenty students with half the students studying biology and half-focused on economics. On the first day, the two professors team-teaching the class shared the course's overarching question, "Why and how should we save salmon populations?" and invited students to engage in collaborative projects, informed by the particular disciplinary expertise they brought to the course, to evaluate the best way to mitigate a local salmon recovery issue.

What made Legg's learning experience transformational was her recognition near the end of the course that the instructors themselves did not actually have an answer to the question they posed at the start of the semester. She then realized that jointly examining that common question-one that was to 
linger beyond the end of the course - was actually the co-inquiry agenda of the course. As a TLA participant, she was able to recognize and name the emergent focus on co-inquiry and became even more convinced that for true co-inquiry to occur, an environment must be created where students explicitly work with instructors to not only explore their shared questions, but also, whenever possible, to help generate them.

The TLA model serves as a powerful framework for enabling learning and demonstrates how coinquiry is a question-making activity, both inside and outside the classroom. The questions lead the way. See the TLA website for a catalogue of recent big shared questions: http://library.wwu.edu/tla. Now, we will examine a second institution that has questions leading the way for its co-inquiry work with students.

\section{Case study 2: co-inquiry in the Wabash-Provost Scholars program at NCAT}

The NCAT Wabash-Provost Scholars Program (WPS) provides another perspective on the importance of shared questions as the foundation for student-faculty co-inquiry at the institutional level. While the TLA's shared questions develop organically in an informal yet structured manner over the course of a full academic year, the WPS has a more traditional look and feel that is currently a creditbearing semester-long course. However, within this course, weekly classes are completely hands-on, with the typical student-faculty hierarchy removed. Faculty co-directors and students form a single co-inquiry team, jointly developing and revising shared questions around a topic of current significance to the university. The question generation, data gathering, analysis, and going public phases of this institutional SoTL process are all completed within a single semester, culminating in a written report and campuswide presentation aimed at providing ground-level perspectives on institutional issues and recommendations for change.

Now in its eighth year, the founders intentionally designed the WPS with student-faculty coinquiry at the core and was initially developed to dig deeper into first-year assessment results from the university's participation in the Wabash National Study of Liberal Arts Education (WNSLAE). Through participation in the WNSLAE, the program's founders became aware of Wabash College's use of trained students to conduct student-led focus groups on their campus and indicated an interest in replicating the initiative at NCAT. Co-authors Simkins and Hornsby, the WPS co-directors, worked with Charles Blaich, director of the Center for Inquiry at Wabash College, and Lee Cuba of Wellesley College, to conduct the initial WPS training in fall 2008. The naming of the group reflects its connection to Wabash College, its intellectual contribution and the institutional importance of this group's co-inquiry work.

Initially, the WPS was a semester-long volunteer program, with students earning service hours to use in meeting university graduation requirements. While this format generally functioned well, at times it became difficult to ensure full participation in the co-inquiry experience, in particular during a semester when participation expanded to 28 students. The co-directors decided that a for-credit, repeatable course would help ensure a more even level of student effort. The course size is now typically 15-20 students although there is no enrollment cap. The added incentive of a grade, even a simple passfail, has had the intended effect of maximizing participation effort, a critical component of the co-inquiry approach employed in the WPS. Most Scholars are multi-semester participants, providing a valuable mix of "senior Scholars" and new participants; veteran Scholars mentor the new Scholars and help set the norms for the group. When the program began, students came from the university Honors Program; in subsequent semesters, co-directors invited students they knew to join the WPS. Currently, the program recruits students through campus announcements and a Scholars-led information session. Scholars need a minimum grade point average (2.8) to join and remain in the program. 
Each semester, in collaboration with the WPS co-directors, Scholars learn to undertake human subjects research, approved by the university's Institutional Review Board (IRB), and develop focus group and survey questions related to that semester's project theme in consultation with campus "clients." They then conduct student focus groups, summarize and analyze the resulting data, create comprehensive data-driven written reports, and present the findings in a public presentation typically attended by students, faculty, staff, and university administrators, including the provost and chancellor. ${ }^{3}$ The process aims to provide critical student-level perspectives that otherwise might remain hidden in policy and program decisions.

Unlike the TLA, the WPS co-directors determine the topic for each semester's co-inquiry project to coordinate with current university priorities and initiatives. However, the Scholars take the lead role in developing the questions grounding the inquiry process in collaboration with the codirectors and other university stakeholders. The Scholars not only develop a comprehensive list of questions to explore but also winnow that list down and further refine the questions after initial pilot testing in early focus group sessions.

The inaugural Scholars investigated a question directly related to the WNSLAE results, which indicated some concerns about students' overall success at the university. Ultimately, they pursued the overarching question: What factors promote or hinder student success at NCAT? Since then, the Scholars have conducted semester-length focus-group-based studies on a variety of teaching-learning topics aimed at improving student learning at the university, including faculty-led supplemental instruction, student time use, and mathematics course redesign. In recent years, the inquiry questions directly relate to the university's strategic goals: enhancing the overall academic environment, increasing the institution's share of transfer students, expanding campus diversity, improving graduate education, and refining the advising process.

\section{The 2015 co-inquiry project}

The fall 2015 WPS topic highlights the students' role in the shared question-making process. The university was in the midst of an institution-wide restructuring process that included new models for student advising. Historically, faculty members advised students majoring in programs within their departments with mixed success. One option was to develop a centralized advising system staffed with professional advisors to complement individual departmental faculty advisers. Over a month, the Scholars met with a variety of staff, administrators, and students during weekly class time to better understand the university's advising process and its importance in promoting student retention and graduation rates. Once they completed this background knowledge gathering, the Scholars developed a large set of questions to use for student focus groups, a student survey, and a faculty survey to explore the benefits and challenges of the current advising system and anticipated perceptions of a new, hybrid centralized/faculty-based system. The Scholars then reduced their list to a set of questions that would provide the best information for the university community on this potential change. The resulting questions allowed the Scholars to present comparative data on student and faculty views of the advising process, expectations and roles of advisors and students, and potential improvements in the system. Throughout this methodical inquiry, students drove the question-making process, informed by institutional review board processes and the knowledge that their results would inform the ultimate decisions made by the university.

Some of the focus group questions asked students to describe their experience with academic advising at the university, the attributes of an "ideal" advisor, the roles and responsibilities of an 
academic advisor, the impact of the advising process on their academic progress, among others. Interestingly, the Scholars found that students yearned for greater connection to their advisors rather than simply meeting during course registration periods. The previous view held by faculty members was that students were interested in meeting with their advisor only to obtain the required code that would allow them to register for next semester's classes. The data clearly showed that students are interested in developing a deeper and more holistic student-advisor relationship that promotes discussion of career choices and personal coaching in addition to the more pragmatic course-scheduling role. This information is valuable in changing faculty perceptions and re-shaping the role of advising on campus.

\section{From co-inquirers to change agents}

Unlike most undergraduate research experiences, WPS participants come from all disciplines, including the sciences, humanities, engineering, and the social sciences, and work together collaboratively to carry out both qualitative and quantitative research. As noted previously, the aim is to both explore issues of strategic importance and provide recommendations to improve the university. The diversity of student backgrounds in the group leads to a genuine student-student and studentfaculty partnership process that communally informs the development of shared inquiry questions. Like the TLA, the WPS, in partnership with the program co-directors, undertake a form of institutional SoTL, focused on institution-level inquiry and question generation, evidence gathering, data analysis, and public sharing of results (see Hutchings, Huber, \& Ciccone, 2011, pp. 79-81, and Kuh, et al., 2015, pp. 110-115 for additional discussion). Grounded in student-faculty co-inquiry, the WPS is an incubator for developing SoTL scholars with the added benefit of providing valuable ground-level feedback on issues of strategic importance to the university.

Thus, similar to the TLA, shared inquiry lies at the center of the WPS. Within the program, students and faculty are co-researchers in a knowledge-generation process aimed at capturing student voices to inform and promote change within the institution. As with the TLA at WWU, this type of coinquiry, centered in shared questions around issues of institutional importance, promotes deep, meaningful learning. Students become researchers exploring their own experiences and those of their peers, providing an authentic learning experience. By asking about and reflecting on the best ways to conduct that research including what questions to ask - in partnership with the faculty co-directors, they gain new insights about themselves as learners, researchers, and change agents. As highlighted by Kuh, et al. (2015), the co-inquiry process - with students working alongside faculty members to address big institutional questions - gives students "a greater sense of agency as learners and an opportunity to be part of something bigger - contributing to changes that will make the institution more effective for other students, now and in the future" (pp. 113-114).

At the end of each co-inquiry project, the WPS complete reflective journals to capture what is working, identify growth-promoting activities, and suggest changes. These Scholar responses consistently demonstrate the transformational impact of the co-inquiry process and program's development of tolerance, collaboration, and self-confidence:

- "I gained more confidence to speak up and not fear others' criticism of my thoughts or ideas."

- "Working with the scholars as a team challenged me to develop... it forced me to step outside of my comfort zone."

- "Learning how to communicate in a team setting contributed to my personal growth... communication skills that are transferable to any career path."

- "Participating in this program has shown me there is no "I" in team." 
- "My first time doing a presentation with the program was the most confident I had ever felt."

- "I've learned how to stay objective when dealing with students even when I feel strongly about the topic."

- "Working in these groups assisted me in how to properly work with others with differing opinions but still getting the job done regardless."

- "I have learned a great deal about working with different personalities and managing conflict maturely."

- "My growth was in the area of collaborating or even talking to those who I felt as though were different."

However, this newfound role as change agents informed by campus-level research is sometimes unsettling, as Kuh, et al. note. The Scholars experienced this first-hand recently, when they explored the role of diversity on the NCAT campus. A historically black university (HBCU), approximately 85 percent of NCAT's student body identifies as African-American. The university's strategic plan calls for greater diversity, moving from 85 to 70 percent African-American students by 2020 .

In their focus groups and later in their public presentation, the Scholars faced significant resistance to this strategic goal (and student challenges in a public question-and-answer session following the presentation), with students concerned that as the percentage of African-American students fell, it would dramatically change the character of the "HBCU experience." The Scholars carried out the research objectively and reported on the data-driven findings and their relationship to the university's strategic goal, while also addressing student preconceptions. This public sharing allowed the university to build on the Scholars' findings by holding town-hall meetings and seeking greater student input on how to best transition into greater campus diversity. Following the public presentation, the chancellor invited the Scholars to present their findings at a Board of Trustees meeting, validating both the quality and importance of their research.

In addition to forming the basis for a Board of Trustees' meeting presentation, the Scholars' work has been recognized both on campus and externally. For example, faculty members at the university frequently cite Scholars' findings and administrators or committees regularly inquire about the Scholars' research. More notably, the Scholars have served as external assessment consultants at other universities, have been cited in a variety of scholarly publications, and have co-led national workshops (at Wabash College) for teams from other institutions interested in developing similar programs on their own campuses. In each case, the Scholars have served a prominent leadership role.

\section{Co-inquiry's impact}

Each semester, some new Scholars express surprise at the intentional co-inquiry framework of the WPS and the flattened student-instructor hierarchy within the program, an experience unlike what they typically encounter in other academic courses. As co-author Franklin, a recently graduated Scholar, notes, "In most research studies as an undergraduate student, you are told what to do and are only allowed to do certain tasks, but as a co-inquirer we are just as involved as our faculty co-directors." This co-creation process is central to the program and builds a sense of shared responsibility, with shared questions at the center. She illustrates this relationship with an analogy: "Being a co-inquirer is synonymous to being part of a relay race. Without everyone running and doing her/his part fully, the race may be lost. Each person's role is vital to the next."

As emphasized throughout, shared questions developed (and researched) jointly by faculty members and students are central to the co-inquiry process. Franklin reflects on this aspect of the 
Scholars program, saying, "Once we have sufficient understanding of the broad topic we are researching for the semester, it is our job (as a team) to develop questions that will provide relevant data regarding that topic — data that will describe students' experiences and inform potential recommendations for change. We really want to get unbiased answers from the participants in our focus groups and surveys."

The process of co-developing and refining research questions is an arduous, but meaningful, task. She continues, "We work tirelessly to word questions so that focus group participants are not led to answer a particular way. Our goal is to capture 'student voices' as objectively as possible." Echoing the importance of research objectivity, a fellow Scholar noted, "The program has taught me the importance of research, the role it plays in the University ... and to become more receptive of opinions contrary to mine."

Overall, while the formal structure of the WPS differs from the TLA, the central role of studentfaculty co-inquiry, framed by shared questions developed in a collaborative manner and focused on issues of institutional importance, is common to both programs. Students-as-co-researchers undergird the processes in both cases, leading to authentic and meaningful learning aimed at institutional change. As evidenced by participant testimonies, the co-inquiry process transforms the student participants, with many attesting to an increased sense of ownership for contributing to their own and others' educational experiences. Students not only gain valuable research, writing, speaking, and listening skills, but they also gain confidence in their ability to apply reasoned, data-driven analysis to matters of public importance and to effect change. Faculty, staff, administrators, and non-university participants gain a greater appreciation for the leadership role that students can play in the life of the university and the profound realization that learning is a process, not an event, and that students can and should play a key role in that process.

\section{Co-inquiry and the scholarship of teaching and learning}

As illustrated in these two case studies, the TLA and the WPS programs are examples of institutional SoTL (Hornsby \& Simkins, 2009), located in the scholarship of teaching and learning category of Healey, Flint, and Harrington's (2014) model of faculty-student partnerships. The programs' focus is on questions of institutional (and community, in the case of the TLA) importance, with the goal of informing and promoting meaningful educational change. The TLA and WPS coinquiry frameworks also involve all four components of the SoTL process as laid out by Huber and Hutchings (2005): (1) developing questions, (2) carrying out the inquiry/gathering evidence, (3) analyzing the data, and (4) public sharing of results. As Huber and Hutchings note, the "going public" component is what "distinguishes the scholarship of teaching and learning from many other approaches to (educational) improvement," such as "institutional research" (p. 27). Moreover, what distinguishes both programs is the resounding emphasis they place on that first component of "developing questions" and the resulting relational dynamics they cultivate.

In these two cases, the collaborative question generation and the student-led public sharing of results are critical components for effecting change. For the TLA, the results of the big question studies are varied and published within the campus community and beyond. The publications have included the creation and circulation of guiding principle documents (such as the Reflective Practices Compendium) as well as proposals that inform meaningful campus initiatives with lasting impact (e.g., implementing the "Connecting Communities" event and launching a Reflective Garden).

For the WPS, going public means developing a written report of Scholars' research findings and sharing those results, along with evidence-based recommendations for change, in a public forum attended by senior administrators, faculty members, and students. In addition, the Scholars have 
regularly presented their research findings at senior administrator meetings as well as to the university's board of trustees. In each case the results have helped to inform campus-level decision-making on a range of issues, including the development of new transfer student services, campus-wide discussions on diversity and inclusion, ongoing revisions to mathematics pedagogy and course design, and modifications of the advising system.

The public sharing of co-inquiry findings is an essential feature of SoTL research. As Huber and Hutchings emphasize, "Going public ... creates new lenses and angles on the entire process and the significance of the work" (p. 28). The research findings resulting from the TLA and WPS studies suggest new ideas and questions for further exploration, along with new ways of carrying out future work in a continuous learning process. What makes this learning process so powerful for all participants in the TLA and WPS programs is that students are co-leading the process, with shared questions and coinquiry at the center.

While the language of students as co-inquirers is relatively new, we hope the experiences shared here illustrate the value of this particular type of co-inquiry as a rich SoTL approach. We are still learning about the most effective ways to implement co-inquiry with students but offer the following principles and practices to guide the work:

- While providing an overarching organizing framework is important to the co-inquiry structure, resist giving students specific questions to research. Instead, provide opportunities for the questions to emerge as part of the co-inquiry process.

- At the same time, be willing to draft research questions together and work to refine them together.

- Recognize that a healthy co-inquiry relationship requires a facilitator who is deliberate in flattening the hierarchy to include individual perspectives and contributions.

- Relinquish primary responsibility for the learning process. Students stand poised and ready to assume shared responsibility if we simply let them.

- Be patient; sometimes the work of co-inquiry requires more time than we anticipate (or even plan for).

- Intentionally include opportunities for formative assessment, time to ask, "How are things going?" Then be open to taking new directions that may not have been obvious at the start. The "students as partners" model is relatively young, and articles in this issue of $T L I$ are helping to expand the "teaching and learning commons" (Huber and Hutchings, 2005) by further detailing the variety of potential partnering models with students as co-inquirers. Werder and Otis (2010), CookSather, Bovill, and Felten (2014), and Healey, Flint, and Harrington (2014 and in this issue) have already made significant contributions to the co-inquiry commons. Our hope is that the TLA and WPS programs described here illustrate how co-inquiry-firmly grounded in the co-generation of shared questions - can provide significant opportunities to incorporate student voices that not only inform and animate institutional change, but also contribute to a deeper understanding of how we can learn best and go public with that work, together with students.

Carmen Werder is former Director of the Learning Commons at Western Washington University, including overseeing its TeachingLearning Academy and is affiliated faculty in the Department of Communication Studies.

Shevell Thibou is the Assistant Director of the Learning Commons and Teaching-Learning Academy at Western Washington University. 
Scott Simkins is an Associate Professor of Economics and co-directs the Wabash-Provost Scholars program at North Carolina A\&T State University.

Karen Hornsby is Coordinator of Liberal Studies: Pre-Law, an Associate Professor of Philosophy, and co-directs the Wabash-Provost Scholars program at North Carolina A\&T State University.

Kali Legg is a 2015 alumna of Western Washington University and Huxley College of the Environment, a former Learning Commons Student Liaison, and participant in the Teaching-Learning Academy.

Tawanna Franklin is a 2015 alumna of North Carolina A\&T State University, a former Wabash-Provost Scholar, and is currently attending Florida State University College of Law.

\section{NOTES}

1. References to the language of "co-inquiry" in the context of SoTL and students surfaced as early as at least 2009 when Carmen Werder and Megan Otis successfully proposed one of the inaugural ISSOTL Special Interest Groups and named it Students as Co-inquirers. Echoes of its use appear frequently in the 2010 volume Engaging Student Voices in the Study of Teaching and Learning (Werder \& Otis, Eds.). Decyk et al. in "Challenges and Caveats" use the word in noting that "coinquiry" is "new and evolving" (p. 49) and also in observing that "sustaining student voices in coinquiry need(s) to be ecological" (p. 59). In "Not the Conclusion," Werder also uses it in characterizing a commonality across the cases in this volume in saying, "how readily transportable the notion of students as co-inquirers of teaching and learning can be" (p. 187).

2. "The Higher Education Act of 1965, as amended, defines an HBCU as "any historically black college or university that was established prior to 1964, whose principal mission was, and is, the education of black Americans, and that is accredited by a nationally recognized accrediting agency." There are currently 102 accredited HBCUs in the U.S. (Source: http://sites.ed.gov/whhbcu/one-hundred-andfive-historically-black-colleges-and-universities/)

3. In the U.S., IRB approval is required to publish the results of this type of research.

\section{REFERENCES}

Bevevino, M., Dengel, J., \& Adams, K. (1999) Constructivist theory in the classroom: Internalizing concepts through inquiry learning. The Clearing House: A Journal of Educational Strategies, Issues and Ideas, 72(5), 275-278.

Cook-Sather, A., Bovill, C., \& Felten, P. (2014). Engaging students as partners in learning and teaching: A guide for faculty. San Francisco, CA: Jossey-Bass.

Decyk, B. N., \& Murphy, M., \& Currier, D. G., \& Long, D. T. (2010). Challenges and caveats. In C. Werder \& M Otis (Eds.), Engaging student voices in the study of teaching and learning (pp. 49-65). Sterling, VA: Stylus.

Ellinor, L., \& Gerard, G. (1998). What is dialogue? In Dialogue: Rediscovering the transformative power of conversation, Hoboken, NJ: John Wiley \& Sons, 19-27.

Felten, P. (2013). Principles of good practice in SoTL. Teaching \& Learning Inquiry, 1(1), 121-125. http://dx.doi.org/10.20343/teachlearninqu.1.1.121

Harland, T., McClean, A., Wass, R., Miller, E., \& Nui Si, K. (2015). An assessment arms race and its fallout: High stakes grading and the case for slow scholarship. Assessment and Evaluation in Higher Education, 40(4), 528-541.

Healey, M., Flint, A., \& Harrington, K. (2014). Students as partners in learning and teaching in higher education. The Higher Education Academy: 12-74.

Healey, M., Flint, A., \& Harrington, K. (2016). Students as partners: Reflections on a conceptual model. Teaching \& Learning Inquiry, 4(2). http://dx.doi.org/10.20343/teachlearninqu.4.2.3

Hornsby, K., \& Simkins, S. (2009). Reframing Institutional Assessment Involving Faculty and Students in SoTL Efforts Focused on Institutional Objectives. Presentation at International Society for the Scholarship of Teaching and Learning (ISSOTL) Conference, Bloomington, IN (Indiana Univ.), October. 
Huber, M., \& Hutchings, P. (2005). The Advancement of learning: Building the teaching commons. San Francisco: Jossey-Bass.

Hutchings, P., Huber, M., \& Ciccone, A. (2011). The scholarship of teaching and learning reconsidered: Institutional integration and impact. San Francisco, CA: Jossey-Bass.

Kuh, G., Ikenberry, S., Jankowski, N., Cain, T., Ewell, P., Hutchings, P., \& Kinzie, J. (2015). Using evidence of student learning to improve higher education. San Francisco, CA: Jossey-Bass.

Rilke, R. M. (1934). Letters to a young poet (M.D. Herter-Norton, Trans.). New York, NY: W. W. Norton and Company. Spronken-Smith, R., \& Walker, R. (2010). Can inquiry-based learning strengthen the links between teaching and disciplinary research? Studies in Higher Education, 35(6), 723-740.

Spronken-Smith, R., Walker, R., Batchelor, J., O'Steen, B., \& Angelo, T. (2011). Enablers and constraints to the use of inquiry-based learning in undergraduate education. Teaching in Higher Education, 16(1), 15-28. doi:10.1080/13562517.2010.507300.

Teaching-Learning Academy. Western Libraries/the Learning Commons. Bellingham, WA: Western Washington University.

Werder, C. (2014). Students as co-inquirers: A long history with deep roots. ISSoTL Blog.

Werder, C., \& Otis, M. M. (Eds.) (2009). Engaging student voices in the study of teaching and learning. Sterling, VA: Stylus.

Werder, C., Thibou, S., \& Kaufer, B. (2012). Students as co-inquirers: A requisite threshold concept in educational development? The Journal of Faculty Development, 26(3), 34-38.

Zahorik, J. A. (1995). Constructivist teaching. Bloomington, IN: Phi Delta Kappa Educational Foundation.

\section{Student Response to “Co-Inquiry with Students: When Shared Questions Lead the Way"}

Engaging in co-inquiry with students, where shared questions serve as the foundation for the coinquiry process, is at the heart of learning with (rather than just "from") students. This relational process sees both instructors and students as co-learners, signaling a change in how many institutions view the teacher-student relationship. In their paper, Werder et al. build on the concept of co-inquiry in the scholarship of teaching and learning (SoTL) and emphasize the importance of relationship building through shared questions, stating, "one question typically leads to another question and thus animates and sustains a relationship across those seeking answers to these questions” (p. 3).

As someone who has participated in co-inquiry projects both as a student and as an instructor, I can attest to the importance of shared questions for supporting co-inquiry projects. Without shared questions, we continue to perpetuate that status quo-where instructors define what matters for teaching and learning and where unequal power relations continue. In reading Werder et al.'s article, I was curious about their thoughts on how we can support instructors to make the shift to co-inquiry with students, when this is not the dominant model within many institutions. How do we ensure that instructors do not "take over" or dominate the co-inquiry process?

In addition to the article's focus on shared questions, I appreciated the discussion of "institutional SoTL" which the authors define as "issues of institutional importance [that] inform institutional change” (p. x). In thinking about how co-inquiry can address issues of institutional 
importance, and in reflecting on the two initiatives (the Teaching-Learning Academy and the WabashProvost Scholars Program) described in the paper, I wonder what institutional SoTL might look like if it were to be sustained across multiple departments, faculties, and units, rather than limited to isolated programs within institutions. How do we (individuals, groups, etc.) scale up institutional SoTL initiatives to reach more than single groups of individuals?

I am also curious about how institutional SoTL initiatives reach students who are perhaps less interested, willing, or likely to participate in these initiatives. This question highlights the issue of student access to SoTL initiatives within institutions. Although the authors explicitly state that both initiatives are open to all students, in my experience, typically self-motivated students and/or students who tend to be excelling academically are the students who seek out or choose to participate in these kinds of initiatives. If this is the case and if institutions want to engage in institutional SoTL, what needs to change?

Lastly, I appreciated the authors' inclusion of a "lessons learned" section to highlight principles and practices for engaging in co-inquiry. Framed within a spirit of relationality, it would have been interesting to see this section written from two separate perspectives (instructor and student) or as a dialogue between students and instructors. For example, what would students say to instructors about principles and practices for engaging in co-inquiry? What would instructors say to students?

Returning to the themes of the paper, perhaps shared questions, relational encounters, and dialogue hold part of the answer to "leading the way" in institutional change.

Roselynn Verwoord is a PhD Student in the Department of Educational Studies at The University of British Columbia, in Vancouver, $B C$, Canada.

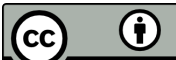

Copyright for the content of articles published in Teaching \& Learning Inquiry resides with the authors, and copyright for the publication layout resides with the journal. These copyright holders have agreed that this article should be available on open access under a Creative Commons Attribution License 4.0 International (https://creativecommons.org/licenses/by/4.0). The only constraint on reproduction and distribution, and the only role for copyright in this domain, should be to give authors control over the integrity of their work and the right to be properly acknowledged and cited, and to cite Teaching \& Learning Inquiry as the original place of publication. Readers are free to share these materials-as long as appropriate credit is given, a link to the license is provided, and any changes are indicated. 